\title{
Dry matter content in silage maize; assessment of the role of growth and water loss
}

\author{
JF Ledent \\ Université Catholique de Louvain, ECOP (Grandes Cultures), 2 place Croix du Sud, B-1348 Louvain-la-Neuve, Belgium
}

(Received 13 February 1989; accepted 6 March 1990)

\begin{abstract}
Summary - Equations for analyzing variations in total dry matter content (MSt) as a function of growth in dry weight and loss of water by plant parts are given. Their use is illustrated in the case of whole plant maize. Calculations of water loss and relative contribution of water losses to increases in MSt are presented. Effects on MSt due to a given amount of growth or water loss by plant parts are predicted. Analysis of experimental data show a decreased contribution of ear growth and an increased contribution of water loss by the stover, as ripening proceeds. Beyond $25 \%$ dry matter content the major part of MSt increase was due to loss of water by the stover.
\end{abstract}

dry matter / silage maize / growth / dessication

Résumé - Teneur en matière sèche du maïs ensilage : évaluation du róle de la croissance et de la dessication. L'évolution de la teneur en matière sèche totale (MSt) en fin de saison est un aspect important de la qualité du maïs destiné à l'ensilage. Celle-ci résulte de processus très différents, la croissance en matière sèche d'une part et la dessication (perte d'eau) de l'autre. De plus, les différentes parties de la plante, grain ou épi et reste de la plante, ne jouent pas le même rôle à cet égard. Cette étude présente une méthode de calcul de limportance relative de ces 2 processus dans les différentes parties de la plante, sur l'évolution de MSt. Les calculs sont basés sur des variations infinitésimales de MSt, mais ils restent suffisamment précis pour des variations finies de l'ordre de quelques \% par intervalle considéré. Les symboles utilisés sont présentés dans l'annexe 3. L'équation (6) donne la relation entre dessication relative (fraction de la quantité totale d'eau perdue), croissance relative en poids sec et variation de MSt. Son utilisation est illustrée par le calcul de la dessication correspondant à une variation donnée de MSt, la croissance relative pendant l'intervalle étant connue. Elle est illustrée également à la figure 2, qui montre l'effet sur MSt d'une croissance ou d'une dessication relative de $1 \%$. L'équation (8) qui en dérive permet de calculer la part relative jouée par la dessication pour une variation donnée de MSt pour autant que la croissance relative soit connue. Elle est illustrée dans le tableau l, pour des intervalles où la croissance relative est de 1\%. L'équation (9) voisine de la précédente indique (fig 1) qu'aux environs de $30 \%$ de MSt, il faut une perte d'eau correspondant à $10 \%$ du poids sec pour augmenter MSt de 1 point. Les équations (13), (14), (16) permettent d'affiner l'étude des variations de MSt en les attribuant à la croissance ou à la dessication des différentes parties de la plante. Le tableau II présente l'effet sur MSt d'une croissance relative ou d'une dessication de $1 \%$ dans l'épi ou le reste de la plante. Pour les valeurs présentées, correspondant à un maiss en fin de saison, une même dessication relative a 3 à 6 fois plus d'effet sur MSt si elle se produit dans le reste de la plante plutôt que dans le grain. Le tableau III montre l'évolution des composantes responsables de la variation de MSt chez le maîs en fin de saison. Tout d'abord, la contribution majeure vient de la croissance en poids sec du grain. Cette part décroît progressivement au profit de celle de la dessication du reste de la plante pour devenir négligeable.

matière sèche / maïs ensilage / croissance / dessication

\section{INTRODUCTION}

The increase in total dry matter content (MSt) of whole plant maize (silage maize) at the end of the season constitutes part of the interrelated processes which take place during ripening. Grain filling, remobilization of carbohydrates from stover to grains, chemical changes in the composition of cell walls, change in digestibility of the stover and water losses occur simultaneously.

Different aspects of these events have been described and discussed in relation to feeding value of whole plant maize and optimum stage of 
harvest for silage (Aerts et al, 1976; Andrieu, 1985; Andrieu and Demarquilly, 1974; De Boever et al, 1983; Deinum and Knoppers, 1979; Ledent, 1986; Struik, 1983; and others).

Since dry matter content (MSt) varies more or less regularly during this period and is relatively easy to measure, MSt is currently used as an indicator of physiological stage or internal status of the plant. Increase in dry matter content is obviously directly related to the continued accumulation of starch in the grains.

There is also some association between MSt and the series of interrelated processes affecting dry matter during ripening. For both these reasons some association between MSt and feeding value may be expected. More directly, low MSt is known to be associated with seepage losses, increased intensity of fermentation in the silo, and decreased ingestibility (Andrieu, 1985; Demarquilly, 1988). A non negligible part of the variation in MSt may, however, be only very loosely related to the internal processes affecting dry matter and feeding value. The tendency of the plant to lose water at the end of season is influenced by senescence but actual losses are also determined by other factors. Water balance in terms of supply of water to the roots and evapotranspiration or more simply dessication at the end of the season affects MSt. Occurrence of diseases affecting root and the base of the stem reduces water supply to the stover and favours dessication. When water loss is an important part of the variation in MSt (comparison of locations, evolution through time, etc) differences in MSt are less likely to correspond to differences in the status of dry matter or physiological stage. Variation in MSt may be analyzed in terms of variations in ear content and dry matter content of ear and stover. Such an analysis is informative, indicating the major effect of slight variation in stover dry matter content (Ledent, 1989). It gives no clues, however, as to the processes responsible for the changes in dry matter content: growth in weight or dessication.

Our objective is to present and illustrate a method for assessing the relative importance of water loss and change in dry weight of plant parts, to account for variations in MSt through time. An analysis of MSt as a function of dry matter content of plant parts and proportions in total weight (eg ear content) has been presented elsewhere (Ledent, 1989).

\section{TOTAL DRY MATTER CONTENT GROWTH AND CHANGE IN AMOUNT OF WATER}

\section{Dividing variations in dry matter content \\ into 2 components: growth \\ and dessication-hydration}

Total dry matter content MSt is defined by:

$$
M S T=P S t /(P S t+E t)
$$

where PSt is total dry weight and Et is total (1) weight of water in the whole plant. In this case MSt is expressed as a number between 0 and 1 . Dry matter content is expressed in percent; $M S t \%$ is given by MSt $\times 100$.

Infinitesimal variation (dMSt) of MSt may be expressed by the total differential ( $\delta$ ) of $M S t$.

$$
d M S t=\frac{\delta M S t \cdot d P S t}{\delta P S t}+\frac{\delta M S t \mathrm{~d} E t}{\delta E t}
$$

The first term of the sum refers to the variation in dry matter content due to change in dry weight (growth); the second term refers to the change in the amount of water contained in the plant. For simplicity we rename these 2 parts $d M S t_{P S t}$ and $d M S t_{E}$, respectively. Thus eq (2) becomes :

$$
d M S t=d M S t_{P S t}+d M S t_{E t}
$$

The fraction (proportion) of the change in MSt which is due to water is given by dMSEt/dMSt.

\section{Assessing the effect of relative growth or relative change in amount of water}

So that the effect of a relative change in dry weight (relative growth) or amount of water may be discussed, we define :

$$
\begin{gathered}
r_{P S t}=P S t^{-1} d P S t \\
\text { relative change in dry weight }
\end{gathered}
$$

where $d P S t$ and $d E t$ represent the infinitesimal change in dry weight and amount of water (respectively). 
Equations (2) and (3) become:

$$
d M S t=(1-M S t) M S t\left(r_{P S t}-r_{E t}\right)
$$

This equation (eq 6) allows general questions to be answered such as what is the effect of a given relative increase in dry weight (say $5 \%$ ), or what would be the effect on dry matter content if the plant loses a given percentage of (say $1 \%$ ) of its water. Note that:

$$
\begin{aligned}
& d M S t_{E t}=(1-M S t) M S t r_{E t} \\
& \text { and } \quad d M S t=\left(1-M S t_{P S t}\right) M S t r_{P S t}
\end{aligned}
$$

\section{Assessing the effect of a change in amount of water from records of MSt, PSt}

Explicit records are frequently available for $M S t$, $P S t$ and therefore $r_{P S t}$ but not for the amount of water $\left(E t, r_{E t}\right)$. Equation (6) may be used to calculate $r_{E t}$ (relative loss of water) from $d M S t, M S t$ and $r_{P S t}$. Similarly, the contribution (dMSt $t_{E t}$ ) of a change in amount of water to a given variation in dry matter content may be obtained using equation (8), derived from (3) and (6):

$$
d M S t_{E t}=d M S t-(1-M S t) M S t r_{P S t}
$$

If the loss of water is expressed relative to total dry weight (by dET/PSt) then equation (9), derived from $(2,3,5)$ :

$$
d M S t_{E t}=-P S t^{-1} M S R \mathrm{~d} E t
$$

may be used.

\section{Application examples}

Strictly speaking, the above equations apply to infinitesimal increments (dMSt, $d P S t$, $d E t$ ) only. For relatively short intervals, with finite increments $\Delta M S t: M S t_{2}-M S t_{1}, \Delta P S t=P S t_{2}-P S t_{1}$, etc, the error in the equations remains negligible (we replace $d M S T$ by $\Delta M S t$, dPSt by $\triangle P S t$, etc).

In the examples that follow, all calculations were made on small finite increments; when ratios such as $M S t^{-1}, \Delta M S t$ had to be calculated the value chosen for $M S t$ was taken as $M S t_{1}$, thus the expression $M \mathrm{Mt}_{1}{ }^{-1}\left(\mathrm{MSt}_{2}-\mathrm{MST}_{1}\right)$ was used. Relative changes were therefore expressed relative to the value at the beginning of the interval of time considered. The values cho- sen in the examples were chosen with regard to whole maize plants during grain filling.

\section{Calculating the relative water loss from records of dry weight and dry matter content}

For example, if during a time interval MSt increases from a value of 0.20 (dry matter content $20 \%$ ) to 0.24 whereas dry weight has increased by $15 \%$, equation (6) gives $r_{E t}:-0.10$; thus the plant has lost $10 \%$ of the water it contained at the beginning of the interval.

In the case of a plant increasing its dry matter content from a value of $25 \%$ to a value of $25.5 \%$ whereas its dry weight increases by $0.4 \%$ the water loss would be $2.2 \%\left(r_{E t}:-0.022\right)$.

\section{Increase in dry matter content due to water loss}

The relative contribution of dessication to increase in MSt is $d M S t_{E l} / d M S t$. Table I shows calculations for intervals corresponding to an increase of $1 \%$ in dry weight, using equation (8) and dividing by $d M S t$. Thus using table I we conclude that if during a given interval (corresponding to an increase of $1 \%$ in dry weight) dry weight content increased from an initial value of $25 \%\left(M S t_{1}: 0.25\right)$ to $26 \%\left(M S t_{2}: 0.26\right.$; increment $d M S T$ is of 0.01 or $1 \%$ ) this was $81 \%$ due to water loss (value read in the table is 0.81 ). If the increase was only from $M S t_{1}=0.25$ to $\mathrm{MSt}_{2}$ $=0.255$, then it was about two thirds $(63 \%)$ due to water loss.

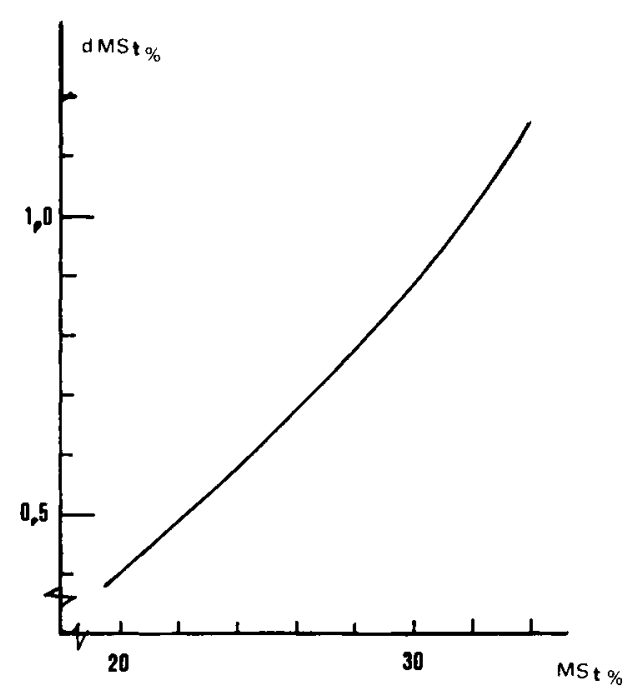

Fig 1. Effect on MSt of the loss of an amount of water weighing as much as $10 \%$ total dry weight. MSt is total dry matter content; MSP is MSt $\times 100 ; d M S \%$ is dMSt $\times 100, d M S t$ being given by (9). 
Table I. Relative contribution ${ }^{1}$ of water loss to increases in total dry matter content. ${ }^{1}$ Calculations based on equation (8). Results are presented for interval corresponding to an increase of $1 \%$ in total dry weight. ${ }^{2}$ MST\% is MST $\times 100$, increment of $M S T \%$ is $d M S T \times 100$.

\begin{tabular}{|c|c|}
\hline & \\
\hline & \\
\hline & \\
\hline $\begin{array}{l}\text { Increment of MST\%2 } \\
\text { during interval }\end{array}$ & Total dry matter content MST $\%^{2}$ at beginning of interva \\
\hline
\end{tabular}

$\begin{array}{lcccc} & 20 & 25 & 30 & 35 \\ 0.25 & & & & \\ 0.5 & 0.36 & 0.25 & 0.16 & 0.09 \\ 1.0 & 0.68 & 0.63 & 0.58 & 0.55 \\ 1.5 & 0.84 & 0.81 & 0.79 & 0.77 \\ & 0.89 & 0.88 & 0.86 & 0.85\end{array}$

\section{Predicting the effect on MSt of a given water loss}

Figure 1, based on equation (9), indicates that $\approx$ $30 \%$ dry matter content $(M S T=0.30)$ a loss of water corresponding to a weight as high as $10 \%$ the total dry weight increases dry matter content (in \%) by about one unit: in this case MSt\% becomes 30.9 and the dMSt\% value read in the figure indicates an increase of 0.9 . Conversely a water loss corresponding to $10 \%$ of total dry weight is required to increase total dry matter content by one unit. When the plant had a dry matter content of $25 \%$ such a water loss increased total dry matter content by 0.6 (dMS \%).

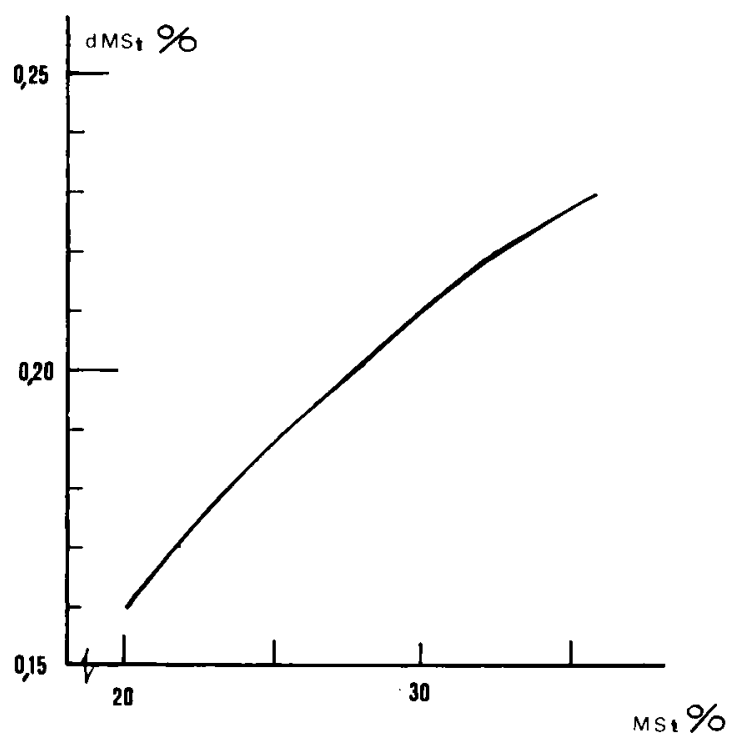

Fig 2. Effect on dry matter content (MSt) of a $1 \%$ increase in dry weight or of a $1 \%$ water loss. MSP is MSt $\times 100$ (total dry matter content); $d M S P \%$ is the increment of MSP corresponding to a $1 \%$ increase in dry weight or a $1 \%$ loss of water. Calculations are based on (6).

\section{Predicting the effect on MSt of a given relative change in dry weight or amount of water (effect of $r_{P S t}$ or $r_{E t}$ )}

According to equation (6) a small increase of $x \%$ (say for example, 1\%) in total dry weight has the same effect on dry matter content as a similar loss of $x \%$ (in this example, $1 \%$ ) of the amount of water present in the plant (fig 2). The magnitude of the effect is presented in figure 2 , for different amounts of initial dry matter content and with $\mathrm{x}=$ $1 \%$.

Thus when a plant with $M S t=0.30\left(\right.$ MSt $_{1} \%=$ 30) loses $1 \%$ of its water or increases its dry weight by $1 \%, M S t \%$ increases by $d M S t \%=$ $0.21\left(M S t_{2} \%=30.21\right)$. When the plant has a $M S t$ of only 0.25 such changes in water or dry weight increase dry matter content by $d M S t \%=0.19$.

\section{ASSESSING THE ROLE OF DIFFERENT PLANT PARTS IN dMST}

\section{Calculating the contribution of growth and change in amount of water of plant parts to dMSt}

The contribution of the different plant parts to growth, and dessication or hydration (variation in amount of water) may differ from part to part. For instance, during the period of grain filling and maturation of maize the contribution of ear or grain (on the one hand) and stover (on the other) obviously differ. 
Let $d M S t_{i}$ be the contribution of plant part $i$ to the variation (dMSt) in total dry matter content. Thus :

$$
d M S t=\sum d M S t_{i}
$$

Note that $d M S t_{\mathrm{j}}$ should not be confused with the variation in dry matter content of plant part $i$ (noted as $d M S_{i}$ ). Applying equation (3) to each plant part $i$ and using (10), we find:

$$
d M S T=\sum_{i=1} n d M S t_{\mathrm{PS} i}+\sum_{i=1} n d M S t_{\mathrm{Ei}}
$$

with $d M S t_{P S i}$ being the contribution of growth in dry weight $P S_{i}$ of part $i$ to $d M S T$ and $d M S t_{E i}$ the contribution of change in amount of water $d E i$ in part $i$. To obtain equations corresponding to (7) and (8) for part i we have to introduce:

$$
P i=P S i / P S t
$$

the proportion of total dry weight being represented by part $i$. Then:

$$
\begin{gathered}
d M S t_{\mathrm{PSi}}=(1-M S t) M S t P S t^{-1} d P S i \\
=P i(1-M S t) M S t r_{\mathrm{PSi}}
\end{gathered}
$$

where $r_{P S i}=d P S t / P S i$ is the relative change in dry weight of plant part $i$. Similarly:

$$
d M S t_{E i}=-(1-M S t) \cdot M S t E_{t}^{-1} d E_{i}
$$

an equation corresponding to (9). This equation may be written in different forms which are more convenient to use with the usual records of dry weights and dry matter content.

$$
\begin{gathered}
d M S t_{E i}=-P S t^{-1} M S R^{2} d E_{i} \\
d M S t_{E i}: P_{\mathrm{i}} M S R^{2} M S_{i}^{-1}(1-M S i) r_{E i}
\end{gathered}
$$

Equation (15) gives the effect of an absolute loss (or gain) of water $\left(\mathrm{dE}_{\mathrm{i}}\right)$ in part $i$ whereas equation (16) gives the effect of a relative change in amount of water in part $i\left(r E_{i}=E_{i}{ }^{-1} d_{i}\right)$. It allows calculation for instance of the change in total dry matter content when the stover loses a given percentage of its water.

In the case of forage maize, the evolution of total dry matter content (MSt) is often discussed dividing the plant into only 2 parts: ear or grain and the rest of the plant (stover). Variation in MSt will therefore be interpreted as the sum of 4 components:
1), contribution of ear growth, in dry weight (using equation 13); 2), contribution of stover growth (which may be negative); 3 ), contribution of change in amount of water contained in the ear or grain (usually this is negative, since dessication occurs; equation 4 is used); 4), contribution of change in amount of water contained in the stover.

Stover contributions (contributions 2 and 4 above) are obtained directly by equations (13) and (14) or (15) applied to the stover. They may also be obtained subtracting the contribution of ears from $d M S t_{P S t}$ and $d M S t_{E t}$. This second method was used in the example given below.

If calculations of $d M S t$ components are made from sequential data of ear content ( $P i$ of ear), dry matter content of ears (MSi of ear), total dry matter content (MSt) and total dry weight (PSt), some preliminary calculations are necessary to obtain PSi of ears (and therefore $d P S i$ ), $E_{t}$ (total amount of water) and $E_{i}$ of ears (amount of water in ears), PSi is obtained from (12) whereas:

$$
\begin{aligned}
& E_{i}=P S i\left(M S_{i}^{-1}-1\right) \\
\text { and } \quad & E_{t}=P S t\left(M S t^{-1}-1\right) .
\end{aligned}
$$

Equations giving the relation between $M S t$, $M S i$ and $P i$ (for ear and stover) have been presented and discussed elsewhere (Ledent, 1989). Some equations are presented in appendix 1.

\section{Applications}

Predicting the MSt variation due to growth (in dry weight) or loss of water by ears or stover

Table II presents dMSt for relative changes of $1 \%$ in dry weight of part $i$ ( $\left.r_{\mathrm{PSi}}\right)$ or in amount of water $\left(r_{E i}: d E i / E I\right)$. For example, with $M S i: 0.50$ for ears and 0.20 for stover, the effect of an increase of $1 \%$ in ear dry weight $\left(r_{P S i}\right.$ of ears = $0.01)$ corresponds to an increase (dMSt) in total dry matter content of 0.00078 . For an increase of $10 \%$ in ear dry weight, the effect is $\approx 10$ fold higher (but the approximation is less accurate because of the larger interval).

Table II shows the higher sensitivity of MSt to dehydration of the stover: for equal relative losses of water, the increase in MSt is 3-6-fold higher than for the same relative loss of water in the kernels. This is to be expected, since the total amount of water contained in the stover is higher than in the grain. When absolute amounts of wa- 
Table II. Effect on total dry matter content of growth or dessication of ears or stovers. a Effects of an increase of $1 \%$ in dry weight of ears or of stover. Calculations are based on eq (13) or appendix 2. b Effect of a loss of water corresponding to $1 \%$ of the amount of water contained in ears or stover. Calculations are based on eq (16). ${ }^{\circ}$ Calculated with equations in appendix 1. d Number presented must be multiplied by $10^{-3}$ to obtain dMST or divided by 10 to obtain dMST\%.

\begin{tabular}{|c|c|c|c|c|c|c|c|}
\hline \multirow{2}{*}{\multicolumn{2}{|c|}{ Dry matter content }} & \multirow{3}{*}{ Ear content } & \multirow[b]{3}{*}{ Total dry matter content } & \multicolumn{4}{|c|}{ Effects of dMST on total dry matter content } \\
\hline & & & & \multicolumn{2}{|c|}{ Effects of growth a } & \multicolumn{2}{|c|}{ Effects of loss of water b } \\
\hline $\begin{array}{l}\text { Ears } \\
\text { MS }_{1}\end{array}$ & $\begin{array}{l}\text { Stover } \\
\mathrm{MS}_{2}\end{array}$ & & & Ear & Stover & Ear & Stover \\
\hline \multirow[t]{4}{*}{0.50} & 0.20 & 0.40 & 0.263 & $0.78^{d}$ & 1.16 & 0.28 & 1.67 \\
\hline & & 0.50 & 0.286 & 1.02 & 1.02 & 0.41 & 1.63 \\
\hline & 0.25 & 0.40 & 0.312 & 0.86 & 1.29 & 0.39 & 1.76 \\
\hline & & 0.50 & 0.333 & 1.11 & 1.11 & 0.56 & 1.68 \\
\hline
\end{tabular}

ter loss $\left(d_{E i}\right)$ are considered, similar amounts of water loss in ears and stover have the same effect on MSt (15). Nevertheless, the capacity of the stover to lose its water is important for the evolution of total dry matter content at the end of the season, and this aspect should be given more attention.

\section{Analyzing field data of $\boldsymbol{M S t}$ through time in terms of ear and stover growth or dehydration}

Examples of analysis of MSt data through time in terms of ears and stover growth and dehydration are presented in table III. The analysis is based

Table III. Contribution of growth and water loss of plant parts to changes (dMST\%) in total dry matter content (analysis of experimental data). ${ }^{1}$ Experimental data from Fronica, The Netherlands (Van der Werf, 1988). Tonus, Belgium, 1988. 2 Exp 1: dates are 12-22/9 (interval 1), 3-12/10 (interval 2), 23/10-2/11 (interval 3). Exp 2: 21/9-12/10 (interval 1), 12-27/10 (interval 2). ${ }^{3}$ Results are expressed in percent of total variation in MSt during the interval.

\begin{tabular}{|c|c|c|c|c|c|c|c|c|c|c|}
\hline \multirow[b]{2}{*}{ Experiment } & \multicolumn{3}{|c|}{ Crop parameters } & \multirow{2}{*}{$\begin{array}{c}\text { Dry matter } \\
\text { content } \\
\text { of ear } \\
\mathrm{MS}_{1}\end{array}$} & \multirow{2}{*}{$\begin{array}{c}\text { Dry matter } \\
\text { content of } \\
\text { stover } \\
\mathrm{MS}_{2}\end{array}$} & \multirow{2}{*}{$\begin{array}{c}\text { Total dry } \\
\text { matter } \\
\text { MSt }\end{array}$} & \multicolumn{2}{|c|}{$\begin{array}{l}\text { Componen } \\
\% \text { contribution } \\
\text { of growth }\end{array}$} & \multicolumn{2}{|c|}{$\begin{array}{l}\text { of dMST \% } \\
\% \text { contribution } \\
\text { of water loss }\end{array}$} \\
\hline & $\begin{array}{c}\text { Interval }{ }^{2} \\
\text { (date) }\end{array}$ & PSt & $P_{1}$ & & & & Ear & Stover & Ear & Stover \\
\hline \multirow[t]{8}{*}{11} & \multirow{3}{*}{1} & 12.37 & 0.280 & 0.250 & 0.167 & 0.184 & \multirow{3}{*}{$102^{3}$} & \multirow{3}{*}{-39} & \multirow{3}{*}{7} & \multirow{3}{*}{30} \\
\hline & & 13.41 & 0.384 & 0.343 & & 0.204 & & & & \\
\hline & & 14.03 & 0.436 & 0.386 & 0.166 & 0.221 & & & & \\
\hline & \multirow[t]{3}{*}{2} & & & & & & \multirow[t]{3}{*}{67} & \multirow[t]{3}{*}{-34} & \multirow[t]{3}{*}{6} & \multirow[t]{3}{*}{61} \\
\hline & & 14.66 & 0.504 & 0.442 & 0.168 & 0.244 & & & & \\
\hline & & 14.47 & 0.516 & 0.459 & 0.188 & 0.270 & & & & \\
\hline & \multirow[t]{2}{*}{3} & & & & & & \multirow[t]{2}{*}{10} & \multirow[t]{3}{*}{-33} & \multirow[t]{2}{*}{20} & \multirow[t]{2}{*}{103} \\
\hline & & 14.11 & 0.540 & 0.489 & 0.198 & 0.292 & & & & \\
\hline \multirow[t]{5}{*}{2} & & 14.50 & 0.392 & 0.361 & 0.154 & 0.199 & \multirow{3}{*}{36} & & \multirow{3}{*}{5} & \\
\hline & 1 & & & & & & & \multirow[t]{2}{*}{-23} & & \multirow[t]{2}{*}{82} \\
\hline & \multirow{3}{*}{2} & 15.00 & 0.472 & 0.434 & 0.172 & 0.241 & & & & \\
\hline & & & & & & & \multirow[t]{2}{*}{9} & \multirow[t]{2}{*}{-12} & \multirow[t]{2}{*}{6} & \multirow[t]{2}{*}{97} \\
\hline & & 14.80 & 0.516 & 0.488 & 0.228 & 0.314 & & & & \\
\hline
\end{tabular}


on (13) and (14). Table III clearly shows the evolution through time of components responsible for variations in MSt. At first, a major contributor to variations in MSt is ear growth (grain growth). This contribution decreases progressively, to be replaced by the effect of water loss by the stover. Obviously, at the end of the season dry matter content variation through time is much more dependent on water loss than on accumulation of dry matter.

Although water loss is partly determined by physiological stage, a large proportion of the variation may be due to short term climatological conditions or disease. The dual role of the stover should be noted: its has a negative effect on MSt evolution due to loss of dry weight, but there is an overwhelming positive effect due to dessication.

\section{CONCLUSIONS}

Analysis of the components of dry matter content variation through time is one of the possible uses of the equations presented in this communication. Such an analysis may be performed routinely once sequential data on total dry weight, ear content, and dry matter content of plant parts are available. It can be applied for comparison of varieties, locations or years. The major role of water loss by the stover in the increase of total dry matter content (MSt) at the end of the season has implications for further study.

Studies of plant traits affecting the capacity of stover to lose water are needed. Due to the importance of water loss in determining the variation in MSt, total dry matter content may not be an adequate parameter for characterizing the physiological age of the plant at the end of the season, in relation to optimal stage of harvest, feed value, etc.

The equations presented also allow assessment or prediction at any time of the effect on MSt of a further change in dry weight or amount of water in any plant part at the end of the season. This may be useful when discussing improvements in MSt through cultivation technique ( $e g$ date of harvest), choice of variety, breeding program, etc.

The analysis presented here does not allow a prediction or simulation to be made of the evolution of dry matter content as a function of climate, etc. It may however indicate the relative importance of the main processes involved and their change through time. Such information should be taken into account when constructing models for evolution of dry matter content.

\section{REFERENCES}

Aerts JV, De Brabander DL, Cottyn BG, Boucque CV, Buysse FX (1976) Evolution de la composition, de la digestibilité et du rendement du maïs en fonction du stade de maturité. Rev Agric 29, 379-430

Andrieu J (1985) Composition et valeur alimentaire du maïs plante entière. Colloque mais ensilage Rennes, AGPM, ITCF, 1-20

Andrieu J, Demarquilly C (1974) Valeur alimentaire du maïs fourrage II. Ann Zootech (Paris) 23, 1-25

De Boever JL, Aerts JV, Cottyn BG, De Brabander DL, Buysse FX (1983) Evolution de la digestibilité et de la valeur alimentaire du maïs en fonction du stade de maturité. Rev Agric 36, 263-271

Deinum B, Knoppers $J(1979)$ The growth of maize in the cool temperate climate of the Netherlands: effect of grain filling on production of dry matter and on chemical composition and nutritive value. Neth J Agric Sci 27, 116-130

Demarquilly C (1988) Variation factors in the Nutritive Value of Silage Maize. Quality of Silage, Digestibility and Zootechnical Performance. CRA Gembloux \& Limagrain, 85-104

Ledent JF (1986) L'importance du grain dans le maïs ensilage. In: Le Maïs en 1985 (Ledent JF, ed) Service technique CIPF and Laboratoire d'Ecologie des Grandes Cultures, Louvain-la-Neuve, 207-216

Ledent JF (1989) Relations entre matière sèche totale et teneur en matière sèche des différentes parties de la plante de maïs. Rev Agric 42, 419-429

Struik PC (1983) Physiology of forage maize (367Zea mays $L$ ) in relation to its production and quality. Pudoc, Wageningen, pp 252

Van der Werf HMG (1988) Het Optimale Oogstijdstip Van Snijmais. Verslag 73, Proefstation Lelystad, pp 51

\section{APPENDICES}

\section{Apendix 1. Calculation of total dry matter content (MSt) from dry matter content of plant parts and ear content.}

For a division into 2 parts (ears 1 and stover 2) we have :

$M S t=\left[(1-P 1) M_{2}^{-1}+P_{1} M^{-1}\right]^{-1} \quad$ (Ledent, 1989) with $P 1$ the ear content, i e the dry weight of ears divided by total dry weight; $M S_{1}$ and $M S_{2}$ the dry matter content of ear and stover, respectively; $M S t$ the total dry matter content.

The general from of this equation is :

$M S t=[\Sigma(P i / M S i)]^{-1}$ 
where MSi is dry matter content of part $i$ and $P i$ proportion of part $i$ on a dry weight basis (dry weight of $i$ / total dry weight). All dry matter contents are expressed as number between 0 and 1 and not in percent.

\section{Apendix 2. Calculation of components of variation (dMSt) in total dry matter content Components are given by :}

$\mathrm{d} M S t=\mathrm{d} M S t_{\mathrm{PS} 1}+\mathrm{d} M S t_{\mathrm{PS} 2}+\mathrm{d} M S \mathrm{t}_{\mathrm{E} 1}+\mathrm{d} M S t_{\mathrm{E} 2}$

derived from (3) and (10)

Effect of ear growth $d M S t_{\mathrm{PS} 1}$ is given by (13)

Effect of stover growth dMStPS2 is given by $\mathrm{d} M S t_{\mathrm{PSt}}-$ $\mathrm{d} M S t_{\mathrm{PS} 1}$

with $\mathrm{d} M S t_{\mathrm{PSt}}$ (effect of whole plant growth) given by (8)

Effect of ear dessication (or hydration) $d M S t_{E 1}$ is given by (15)

Effect of stover dessication (or hydration) $\mathrm{d} M S t_{\mathrm{Er}}$ is given by $\mathrm{d} M S t-\mathrm{d} M S t_{\mathrm{PSt}}-\mathrm{d} M S t_{\mathrm{E} 1}$

Input data for these caculations are values (through time) of dry matter content of ear and stover, ear content and total dry weight.

\section{Appendix 3. Symbols used}

$d E i, d E t, d P S i, d P S t$

infinitesimal variation in $E i, \ldots P S i$, etc
Note that dessication corresponds to negative values!

For approximation, we use the same symbols for finite but small variations

$\mathrm{d} M S t$ infinitesimal variation in $M S t$

$\mathrm{d} M S t_{\mathrm{Ei}}, \mathrm{d} M S t_{\mathrm{Et}}$, etc

subscript indicates the factor $E i$, etc, responsible for the change in MSt. For example, dMSt $t_{E 1}$ is the variation in MSt associated with $E_{1}$, a change in the weight of water contained in the ears.

Ei, Et

weight of water contained, part $i$, and whole plant (respectively)

MSi, MSt

dry matter content of part $i$ and whole plant (respectively), expressed as dry weight/fresh weight (number between 0 and 1)

MSt\%

dry matter content in percent (MSt $\times 100)$

$P_{1}, P i$

proportion of ears (ear content) or of part $i$ respectively (dry weight of i/total dry weight)

$P S_{1}, P S i, P S t$

dry weight of ears, part $i$, and whole plant (respectively)

$r_{\mathrm{Et}}$ or $r_{\mathrm{Ej}}$ relative change in weight of water contained in the whole plant $\left(E t^{-1} \mathrm{~d}_{E t}\right)$ or in part $\mathrm{i}\left(E i^{-1} \mathrm{~d} E I\right)$

$r_{P S t}$ or $r_{P S i}$

relative increase in total dry weight $\left(P S t^{-1} \mathrm{~d} P S t\right)$ or in weight of part i $\left(P S r^{-1} \mathrm{~d} P S i\right)$, respectively. 